\title{
ANÁLISE DAS PROPRIEDADES ÓPTICAS DE FILMES FINOS NITRETO DE SILÍCIO OBTIDOS POR MAGNETRON SPUTTERING *
}

João Luís Aguiar de Abreu ${ }^{1}$ Ladário da Silva²

\section{Resumo}

A aplicação de vidros planos com eficiência energética está aumentando de forma significativa no mercado mundial. A performance energética, bem como as propriedades estéticas, cor, reflexão e transmissão, são os motivos pelos quais estes vidros são aplicados na construção civil. Estes vidros planos com eficiência energética são produtos constituídos por uma lâmina de vidro tipo Soda-Cálcio revestida por filmes finos em escala nanométrica. Tais filmes finos são em sua maioria constituídos de ligas metálicas, metais puros e materiais cerâmicos, como óxidos e nitretos. As propriedades físicas e químicas de cada camada afetam diretamente as propriedades ópticas e a performance do produto. Este trabalho tem por objetivo o estudo das propriedades ópticas de filmes finos de Nitreto de Silício, depositados por Magnetron Sputtering Reativo sobre substrato de vidro Soda-Cálcio.

Palavras-chave: Magnetron Sputtering; Nitreto de Silício; Espectrofotometria.

\section{ANALYSIS OF SILICON NITRIDE THIN FILMS OPTICAL PROPERTIES OBTAINED BY MAGNETRON SPUTTERING}

\section{Abstract}

The application of flat glass with high energy performance has growing around the world. The energy performance, and the aesthetics, such as color, reflection, transmission, are the main reason to apply this kind of glass on the buildings. This flat glass with high performance energy is normally made by means of a flat glass pane coated with one or more layers with nanometric thickness. The thin films are usually composed mainly by metal alloys, metals, and ceramic materials, such as oxides and nitrides. The physical and chemical properties associated to each layers considerably impact the final product performance. The aim of the present study is to evaluate the optical properties of Silicon Nitride thin films deposited on SodiumCalcium glass substrate by Magnetron Sputtering.

Keywords: Magnetron Sputtering; Silicon Nitride; Spectrophotometry.

1 Engenheiro Mecânico, Mestrando em Engenharia Metalúrgica, Programa de Pós-Graduação em Engenharia Metalúrgica (PPGEM), Escola de Engenharia Industrial Metalúrgica de Volta Redonda (EEIMVR), Universidade Federal Fluminense (UFF), Volta Redonda, RJ - Brasil.

2 Físico, Doutor em Física, Professor, ICEX, UFF, Volta Redonda, RJ - Brasil. 


\section{INTRODUÇÃO}

A aplicação de filmes finos manométricos de nitreto de silício em vidros planos possui grande abrangência no que tange às propriedades ópticas de vidros planos utilizados na construção civil. Estes vidros são muito utilizados em função de suas propriedades estéticas, especificamente cor, transmissão e reflexão, mas também devido a sua eficiência energética, ou seja, sua capacidade de reduzir a energia térmica transmitida para um ambiente, ou conservá-la no ambiente [1]. Estes vidros com eficiência energética são normalmente constituídos de uma lâmina de vidro plano revestido por uma ou mais camadas de filmes finos com espessuras nanométricas, constituídas em sua maioria por materiais metálicos e cerâmicos [1]. É de grande interesse por parte da indústria o desenvolvimento de filmes finos que otimizem as propriedades energéticas e ópticas alinhadas com propriedades estéticas, e viáveis economicamente ao que tange os custos do processo produtivo, de forma que crie valor de longo prazo para os clientes, consumidores de vidros planos, e para a sociedade. As propriedades as quais a indústria busca, atualmente, optimização referente aos filmes finos depositados sobre lâminas de vidro são: uniformidade de espessura, isotropia da composição, baixa rugosidade na superfície, adesão, e resistência química e mecânica quanto a abrasão [2]. Este trabalho tem por objetivo estudar as variações das propriedades ópticas em função da variação da espessura filmes finos de nitreto de silício, bem como verificar os efeitos das interfaces entre filmes finos de nitreto de silício. Estes filmes finos de nitreto de silício serão depositados sobre substratos de vidro tipo Soda Cálcio, através da técnica de Magnetron Sputtering Reativo [4]. As propriedades do mesmo serão estudadas e analisadas através das técnicas de espectrofotometria. Sendo bem-sucedidos nesta etapa inicial, pretendemos futuramente investigaremos a variação das propriedades ópticas em função da variação das vazões de gases (Argônio e Nitrogênio), os quais em conjunto com um alvo de silício, geram filmes finos de nitreto de silício, neste caso, o objeto em estudo.

Utilizamos um método interferométrico para caracterização do filme fino de nitreto de silício, a fim de possibilitar a medida da espessura d em função do comprimento de onda e do índice de refração $n$ do filme [1,5].

Imaginemos uma camada de filme fino depositada sobre um substrato. Quando a luz incide a partir do ar, de índice de refração $n_{1}=1$, na superfície de filme fino de índice $\mathrm{n}_{2}$, parte é refletida, parte é transmitida e parte é absorvida. A onda transmitida encontra a interface do substrato e novamente é transmitida e refletida. A interferência entre os feixes que sofrem várias reflexões no interior do filme resulta num padrão de transmitância do sistema que varia com o comprimento de onda da luz incidente. Este padrão depende da espessura $d$ e do índice de refração $n$ do filme fino. Utilizando as expressões para os coeficientes de reflexão e de transmissão na superfície de dois materiais obtidos a partir das condições de contorno, podemos determinar a transmitância e refletância final do sistema $[5,6]$.

A dependência de $n$ com o comprimento de onda (ou frequência) é um efeito que leva o nome de dispersão. As propriedades ópticas de um material mudam ou afetam as características da luz que passa através deste, modificando sua direção e ou intensidade. O índice de refração " $n$ " e o coeficiente de extinção "k" são duas das mais importantes propriedades ópticas. Em um material onde uma onda eletromagnética pode perder energia durante sua propagação, o índice de refração se torna um número complexo. O índice de refração é a parte real e o coeficiente de 
extinção a parte imaginária. O último está relacionado com o coeficiente de absorção [4]. O coeficiente de absorção " $\alpha$ " descreve o quanto a intensidade de um feixe de energia, em determinado comprimento de onda, é reduzida ao passar por um material. A escolha do parâmetro " $k$ " ou " $\alpha$ " depende da informação desejada. Um dos mais convenientes e populares métodos de medidas ópticas envolve passar luz monocromática por uma amostra fina e medir a intensidade da luz transmitida em função do comprimento de onda usando um espectrofotômetro. Existe uma relação simples para determinação do coeficiente de extinção de filmes finos pouco absorventes depositados em substrato de vidro, dado pela Equação 1 [6].

$$
(1-R) / T=\exp (4 \pi k d / \lambda)
$$

Onde, T é o espectro de transmitância em função do comprimento de onda, $\mathrm{R}$ é o espectro de refletância em função do comprimento de onda, d é a espessura do filme e $\lambda$ é o comprimento de onda. Quando um feixe luminoso incide em um meio transparente, como uma placa de vidro, a onda confronta-se com um enorme número de átomos densamente distribuídos que irão dispersá-la. Em meios densos, as ondas dispersas anulam-se em todas as direções, menos na direção de propagação, única direção que se propaga o feixe luminoso. Esta é a situação em todos os casos em que não existe descontinuidade, o que não é o caso na superfície de separação entre meios transparentes, como ar e vidro. Quando um feixe luminoso incide em tais interfaces, uma parte da energia é sempre retro dispersa, fenômeno que recebe o nome de reflexão [6]. Neste trabalho mediremos inicialmente a transmitância (T), espessura do filme fino (d) e o índice de refração $(n)$ e o coeficiente de transmissão $(k)$ dos filmes finos de nitreto de silício depositados por Magnetron Sputtering [7].

\section{MATERIAIS E MÉTODOS}

Foram utilizados substratos de vidro do tipo soda-cálcio (vide Figura 1) com $4.0 \mathrm{~mm}$ de espessura. As amostras possuem o formato de um quadrado com $100 \mathrm{~mm}$ de lado, sendo essas cortadas a partir da região central de uma folha padrão comercial com $2600 \mathrm{~mm}$ de largura e $3210 \mathrm{~mm}$ de comprimento. A composição típica do vidro

Soda-Cálcio é apresentada na

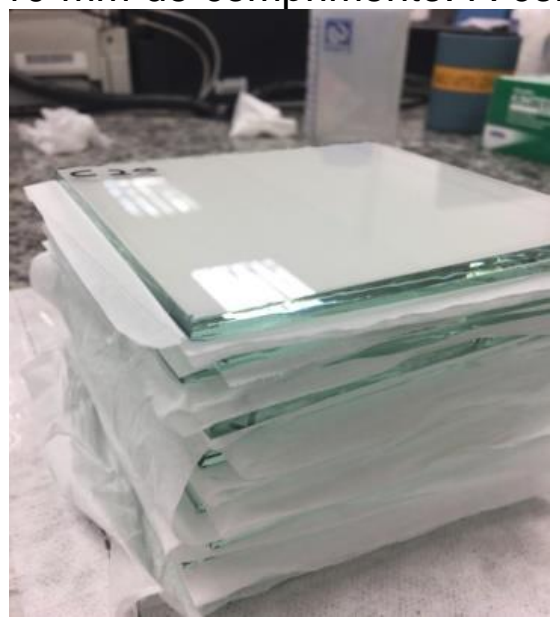

Figura 1. Amostras de vidro tipo soda cálcio revestido de filme fino de nitreto de silício de $60 \mathrm{~nm}$.

Tabela 1, contudo pequenas variações entre diferentes fabricantes devido aos processos e matérias primas utilizadas podem ser observadas [5]. 


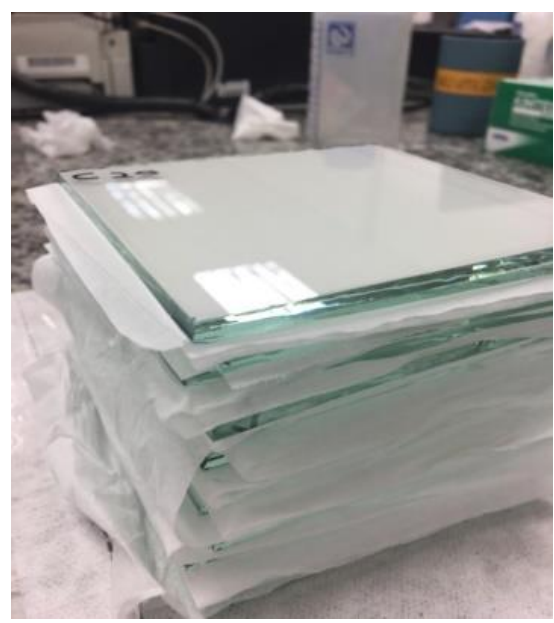

Figura 1. Amostras de vidro tipo soda cálcio revestido de filme fino de nitreto de silício de $60 \mathrm{~nm}$.

Tabela 1: Composição típica do vidro tipo Soda-Cálcio.

\begin{tabular}{llc}
\hline \multicolumn{1}{c}{ Composto } & Fórmula & Proporção em Massa [\%] \\
\hline Dióxido de Silício & $\mathrm{SiO}_{2}$ & 72,8 \\
\hline Óxido de Cálcio & $\mathrm{CaO}$ & 8,6 \\
\hline Óxido de Sódio & $\mathrm{Na}_{2} \mathrm{O}$ & 13,8 \\
\hline Óxido de Magnésio & $\mathrm{MgO}$ & 3,6 \\
\hline Óxido de Alumínio & $\mathrm{Al}_{2} \mathrm{O}_{3}$ & 0,7
\end{tabular}

Os catodos utilizados no processo de deposição, compostos de silício dopado com alumínio, são alimentados por fontes de potência de corrente alternada, com alta frequência associada. Para as medidas das propriedades ópticas, utilizamos o espectrofotômetro Ultra Scan Pro, da marca Hunter, o qual é operado através do Software Easy Match. Este espectrofotômetro possui faixa útil de espectro de 350 a $1050 \mathrm{~nm}$. O mesmo é capaz de nos fornecer valores de transmissão e reflexão, os quais são manipuláveis através de softwares, como o próprio Easy Match [5], ou softwares de simulação para a devida modelagem e obtenção do índice de refração e espessura do filme fino.

\section{RESULTADOS E DISCUSSÃo}


Os resultados apresentados foram obtidos através de espectrofotometria, resultando em espectros de transmissão, reflexão considerando o lado do substrato, e reflexão considerando o lado filme do substrato. Depois estes valores foram manipulados em um software de simulação para medição da espessura das camadas [5], e geração de dados comparativos entre os espectros gerados. Os filmes finos foram depositados utilizando fontes de potência do tipo AC, com potência total aproximada de $150 \mathrm{~kW}$ e vazão total de gases em torno de $500 \mathrm{sccm}$. As figuras 2, 3 e 4 exibem as medidas do espectrofotômetro as quais são respectivamente a transmitância, a reflectância do lado filme e a reflectância do lado vidro. Elas são médias de 26 amostras.

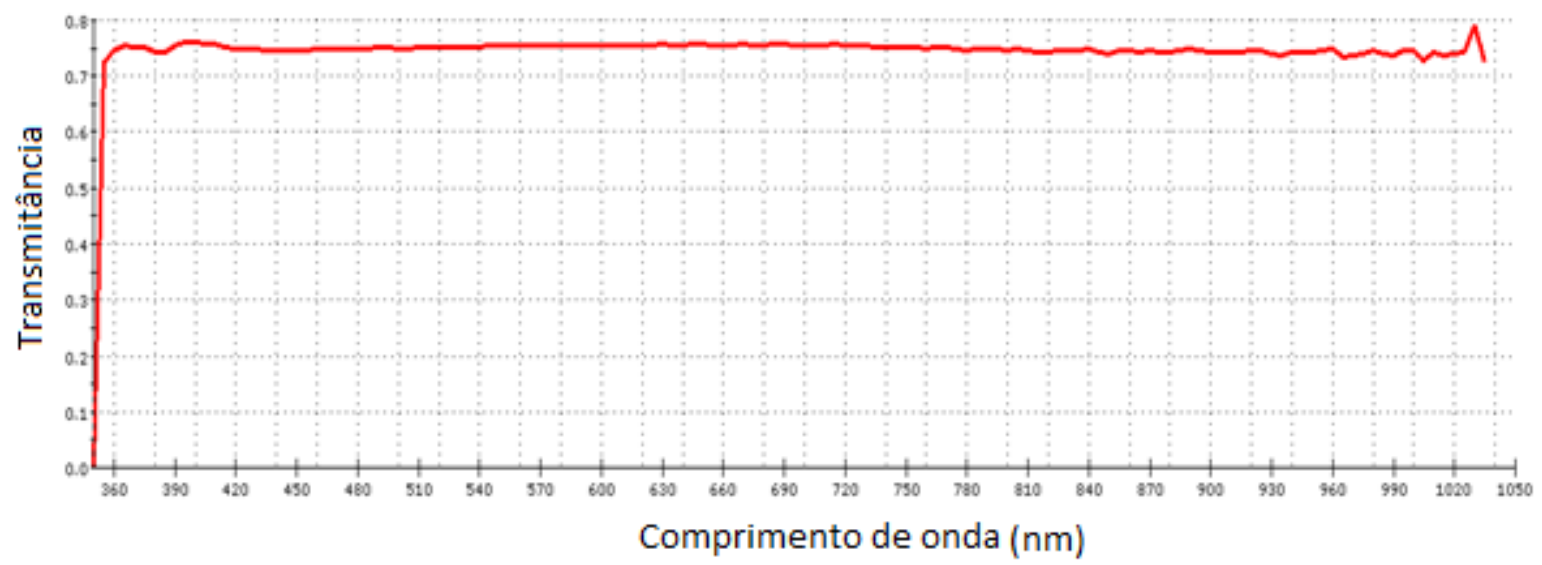

Figura 2. Transmitância de amostra de filme fino de $60 \mathrm{~nm}$ de nitreto de silício sobre substrato de vidro tipo soda-cálcio.

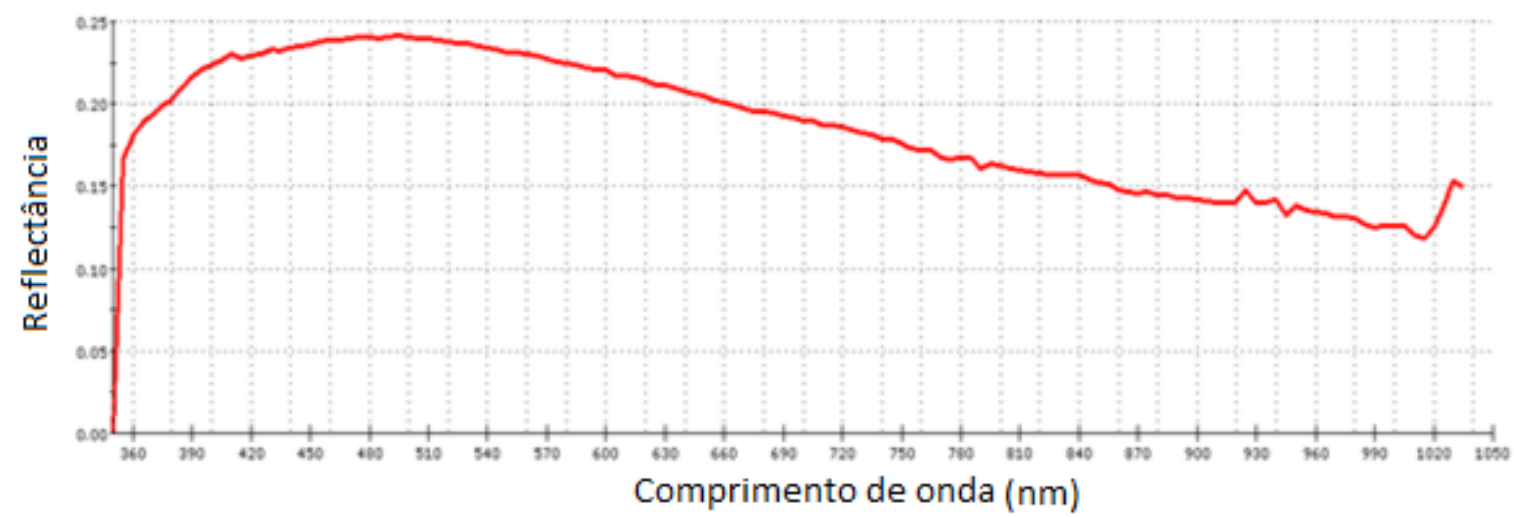

Figura 3. Reflectância de amostra de filme fino de $60 \mathrm{~nm}$ de nitreto de silício sobre substrato de vidro tipo soda-cálcio, medida no lado filme 


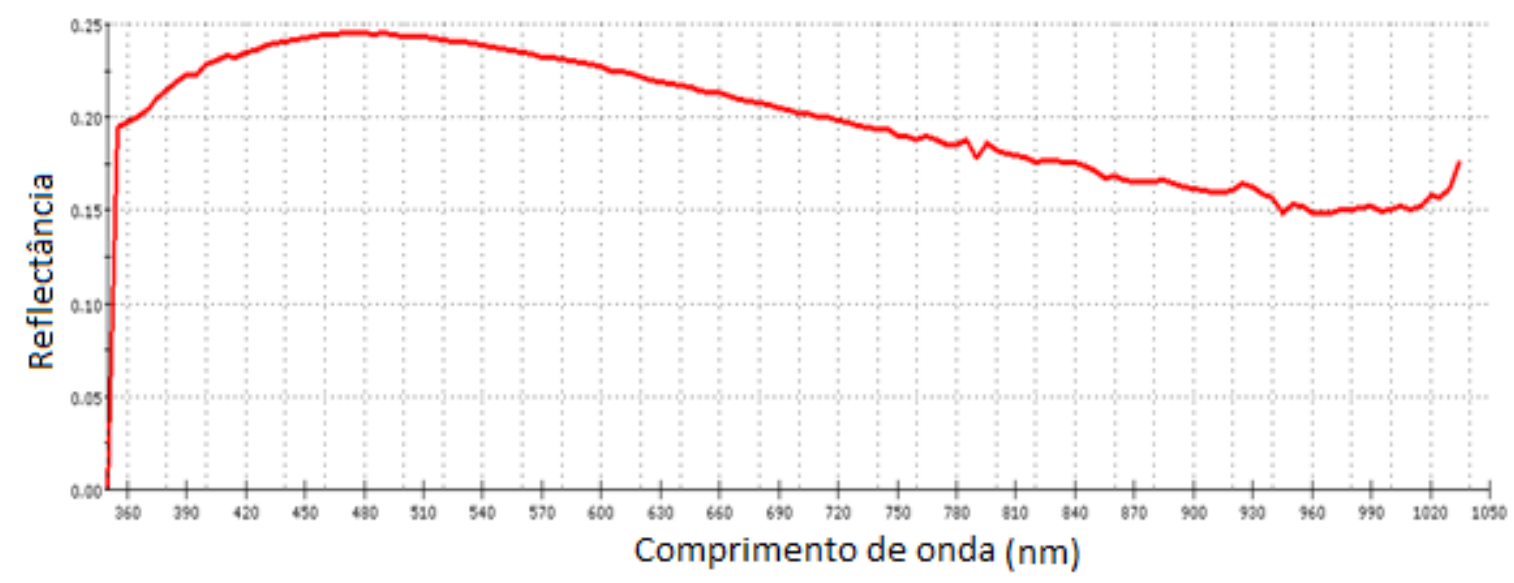

Figura 4. Reflectância de amostra de filme fino de $60 \mathrm{~nm}$ de nitreto de silício sobre substrato de vidro tipo soda-cálcio, medida no lado vidro.

Percebe-se um valor significativo de transmitância para um filme de espessura nominal de $60 \mathrm{~nm}$. A espessura do filme fino depositado foi medida nas 26 amostras de $100 \mathrm{~mm}$ por $100 \mathrm{~mm}$. A maior variação para o filme de espessura nominal de 60 $\mathrm{nm}$ foi de $1.1 \mathrm{~nm}$, como se observa na Figura 5, mostrando desta forma uma excelente performance no processo de deposição. Comportamento similar ocorreu com as propriedades ópticas, pois o índice de refração teve uma máxima variação de $0.01 \mathrm{~nm}$, como se observa nas figuras 6 . O coeficiente de extinção, não mostrado aqui, se manteve constante em zero.

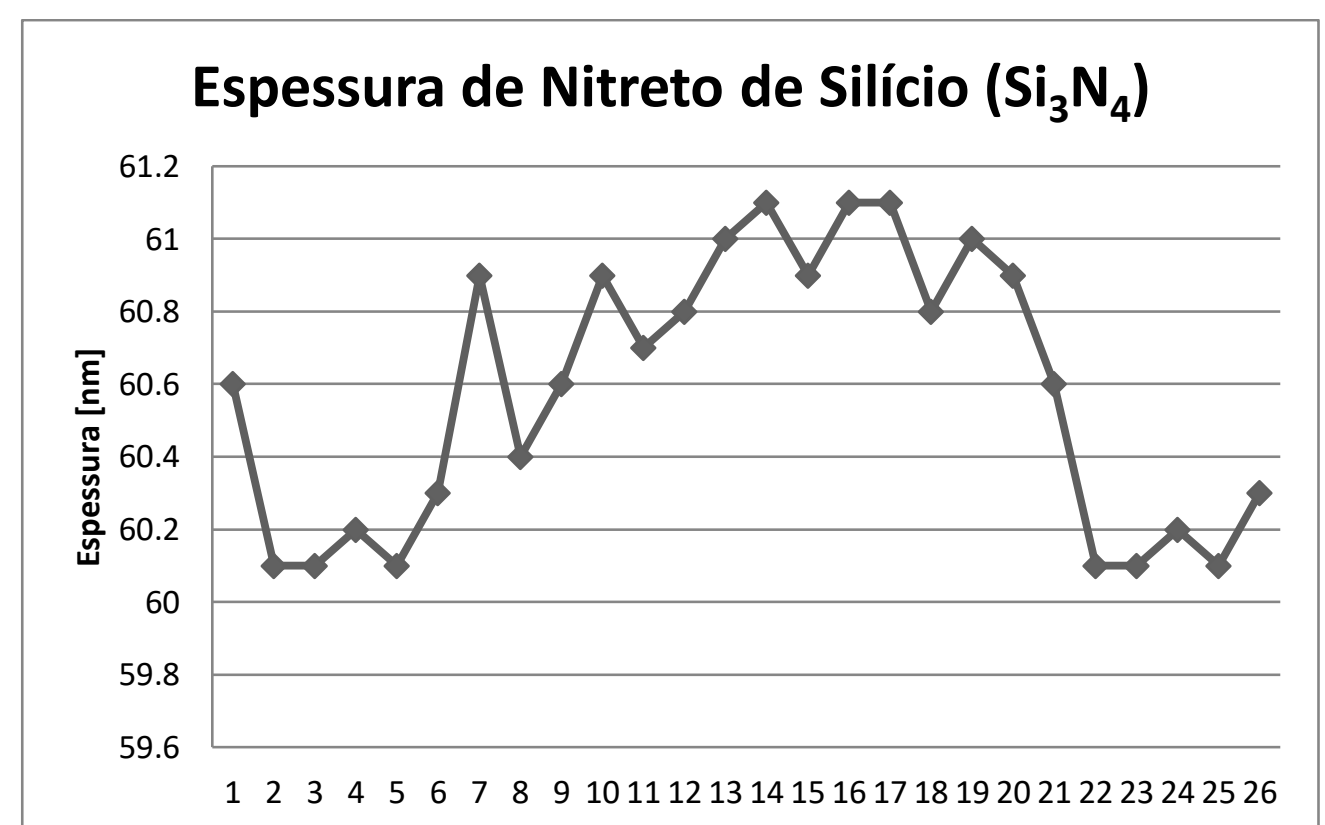

Figura 5. Espessura de filme fino de nitreto de silício sobre substrato de vidro tipo soda-cálcio obtido através de processo de Magnetron Sputtering Reativo, para cada uma das 26 amostras. 


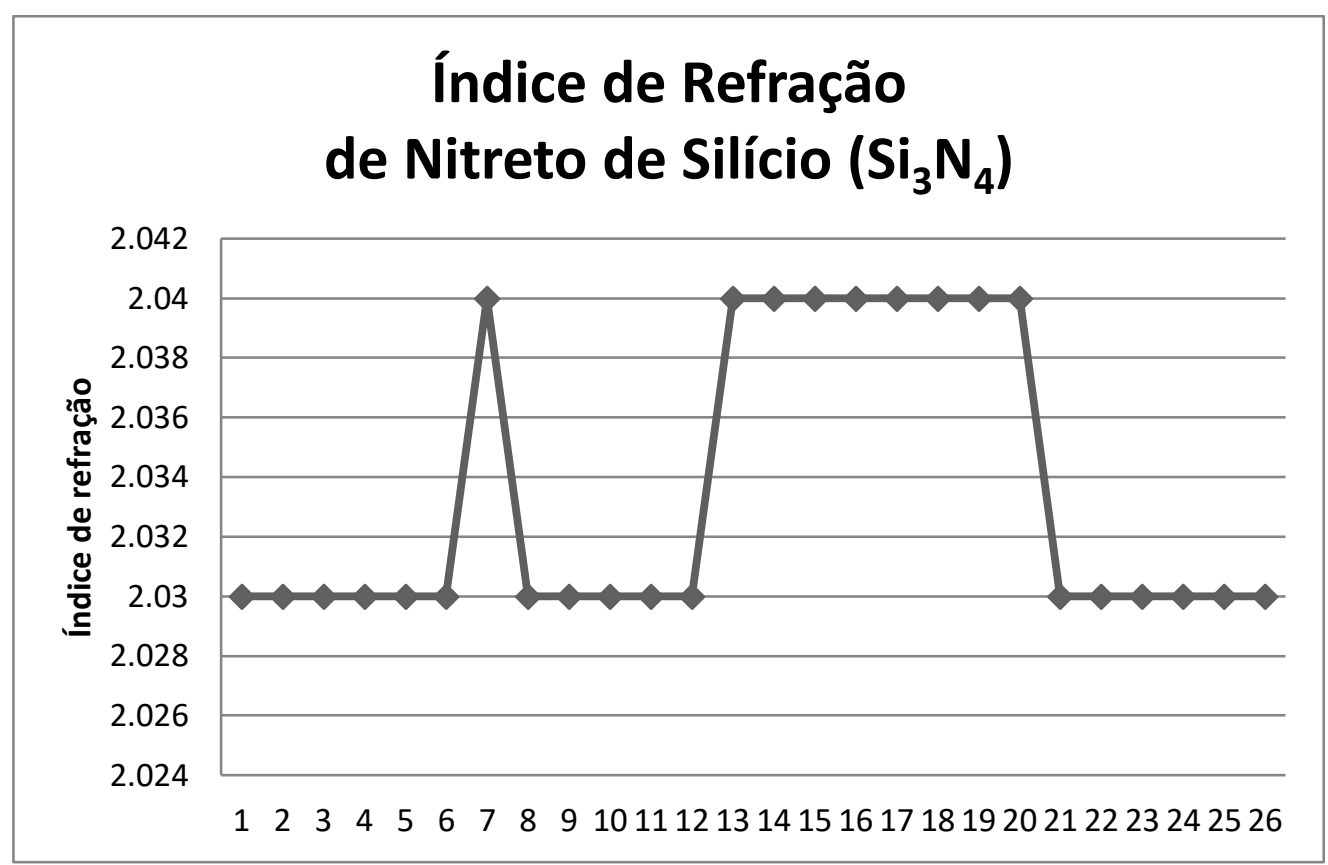

Figura 6. Índice de refração de filme fino de nitreto de silício de $60 \mathrm{~nm}$ sobre substrato vidro tipo soda-cálcio de $4 \mathrm{~mm}$, para cada uma das 26 amostras.

A próxima etapa deste trabalho pretende investigar e efeito da variação das vazões de gases (Argônio e Nitrogênio), da potência e da velocidade de deposição nas propriedades ópticas dos filmes finos de nitreto de silício por Magnetron Sputtering Reativo [7].

\section{CONCLUSÃO}

Neste trabalho usamos a técnica de espectrofotometria para caracterizar filmes finos de nitreto de silício $\left(\mathrm{Si}_{3} \mathrm{~N}_{4}\right)$ depositados por Magnetron Sputtering sobre vidro sodacálcio. Obtivemos as propriedades ópticas assim como medimos a espessura dos filmes finos de nitreto de silício. Verificou-se que a deposição de filmes de nitreto de silício $\left(\mathrm{Si}_{3} \mathrm{~N}_{4}\right)$ pela técnica de Magnetron Sputtering Reativo manteve tanto a espessura do filme fino de forma uniforme em grandes áreas, assim como as propriedades ópticas uniformes em toda a área depositada. Partiremos agora para a variação de outras propriedades da deposição a fim de avaliar seu efeito nas propriedades ópticas dos filmes finos.

\section{REFERÊNCIAS}

1 Kreling A; Estudo do efeito da espessura e da temperatura de recozimento nas propriedades ópticas e morfológicas de filmes finos de nitreto de silício. Dissertação de Mestrado. Universidade Federal Fluminense, Volta Redonda-RJ, 2015.

2 Gläser HJ. Large Area Glass Coating. Von Ardenne Anlagentechnik GmbH, 2000.

3 Bräuer G. Large area glass coating. Surface \& Coatings Technology 1999; 112:358365.

4 Scheidt G. Caracterização óptica de filmes finos de NbOx obtidos por sputtering reativo. São Paulo. Ipen. 2014. 
5 Hilker JN. Short course on Data Analysis for Spectroscopic Ellipsometry. Lincoln, Nebraska, 2003.

6 Born M, Wolf E. Principles of optics: electromagnetic theory of propagation, interference and diffraction of light. 6. ed. Cambridge University Press, 1997.

7 Bultinck E, Bogaerts A. Particle-in-cell/Monte Carlos collisions treatment of an $\mathrm{Ar} / \mathrm{O} 2$ magnetron discharge used for the reactive sputter deposition of TiOx films. New Journal of Physics. 2009;11: 103010. 